\title{
SOBRE LA HIBRIDACIÓN ENTRE ANARQUISMO Y ACADEMIA
}

A propósito de VV.AA, Contemporary Anarchist Studies. An Introduction anthology of anarchy in the academy, London, Routledge, 2009, 318 págs. ${ }^{1}$

Aun cuando aparentemente en los círculos intelectuales oficiales se sepa muy poco acerca de la(s) historia(s) y la(s) teoría(s) de los movimientos anarquistas, parece inquietante establecer una hibridación entre dos cosas, en principio tan diferentes, como son el mundo del anarquismo y el mundo de la academia. Ya en los años setenta, el anarquista Diego Abad de Santillán diagnosticaba en el prólogo de un libro: «El anarquismo, como humanismo, tiene hoy más vigencia que nunca, más que en la época de su entrega al movimiento obrero, más que en las explosiones de rebelión heroica, más que en la actuación ejemplar en la guerra. Se comprueba su resurgimiento en el pensamiento moderno, en la filosofía, en la sociología, entre los economistas, entre los pensadores de todas las lenguas y de todos los climas; en la juventud inconformista que sacude los viejos pilares de una sociedad que se resiste a ser comunidad. Todo ello será y deberá ser reforzado por el anarquismo como bandera humanista, un anarquismo sin adjetivos. En él está la raíz y la fuerza para construir un mundo mejor, el mundo del siglo XXI en el que vivimos ya $»^{2}$. Citamos al anarquista español porque creemos que en sus palabras está contenida la clave del libro que vamos a reseñar. Hablar hoy de "anarquismo sin adjetivos" es descubrir la riqueza y la heterogeneidad de un sinfín de movimientos anarquistas cuyo carácter global inunda todas las esferas de la vida, creando desde esa variedad un proyecto único humanista: dotar de alma a aquello que por definición -se nos dice-, es desalmado, esto es, la maquinaria capitalista.

1. En lo que sigue C (la traducción de las citas es mía).

2. Miró, Fidel, El anarquismo, los estudiantes y la revolución, México, Editores Mexicanos Unidos, 1969, pp. 20-21. 
Del análisis de esos movimientos han emergido una serie de disciplinas universitarias que han cambiado (o están cambiando) la manera de entender la teoría, la metodología, la pedagogía y, por último, la forma de estudiar e interpretar la práctica del anarquismo y su futuro. Contemporary Anarchist Studies se encarga de compilar a través de más de una treintena de colaboraciones, lo que están haciendo estudiantes, profesores universitarios, investigadores independientes y activistas en torno al anarquismo. Ahora bien, conviene tener presente que aunque la estructura de este libro vaya del anarquismo teórico y pedagógico al anarquismo de las calles, lo cierto es que la estructura más natural habría sido aquella que va de lo práctico a lo teórico, o sea, de las calles a la academia. Utilizando una metáfora de la biología podemos decir: la función hace al órgano. Por lo tanto, el resurgimiento del estudio del anarquismo no obedece a un incremento del interés por el anarquismo (que también lo hay) sino que la consecuencia del aumento de dicho estudio viene dada por la praxis: «La teoría anarquista ha estado siempre íntimamente ligada a su práctica» (C, p. 9). O dicho de otro modo, los discursos académicos no han cambiado la realidad sino que la realidad ha cambiado los discursos académicos: «Además, el anarquismo ha crecido en teoría, como resultado de su relación con otras perspectivas. La teoría queer, la teoría crítica de la raza, el feminismo, el ecologismo radical, la liberación animal, el post-estructuralismo, y una multitud de otras perspectivas han dejado marcas indelebles en las teorías anarquistas contemporáneas» (C, p. 9). Dentro de esa complejidad teórica contemporánea, uno de los retos intelectuales más importantes está en saber adaptarse a las novedades sin renunciar a los principios anarquistas; esa adaptación viene dada, en primer lugar, por la reflexión sobre «[...] la posibilidad (o imposibilidad) de una metodología anarquista» (C, p. 71).

Para empezar, se nos dice que hay que hacer sospechosos los métodos más extendidos dentro del humanismo. Para estos colaboradores, sería demasiado ingenuo pensar que los métodos de las ciencias sociales escapan al modelo impuesto por el capitalismo; ese modelo estaría fomentado una ideología acrítica, no destructiva con los valores del capital. Ahora bien, destruir esos valores tiene un precio intelectual, así sucede -como señala Jeff Ferrell- que si uno no investiga según los métodos oficiales, está condenado a que su trabajo, misteriosamente, padezca un «estreñimiento burocrático y un retraso en su carrera» ( $C$, p. 76). Además de este boicot más o menos encubierto, el modelo clásico, al seguir los puntos marcados por el sistema capitalista se hace estéril socialmente por varios motivos: 1) El método clásico cae en el solipsismo por usar un lenguaje exclusivo e incomprensible para el gran público (C, p. 78). Es un método deshumanizado ( $C$, p. 79) donde se fomenta la "tiranía" de las matemáticas, de las fechas, de los datos, de los hechos... sin tener en cuenta un amplio abanico 
de cosas que se niegan o se relegan a una indiferencia ideológica: «sentimientos, actitudes y circunstancias vitales» son un ejemplo de cuestiones subordinadas o académicamente poco estudiadas desde un punto de vista humanista. Este olvido de lo humano provoca indiferencia, frialdad y desconocimiento de los problemas que en realidad conciernen al imaginario colectivo. El modelo clásico también separa la teoría y la praxis, mientras que por ejemplo, Paul Routledge, apuesta por vivir la teoría más allá de las palabras, por el poder de la disensión, por el conflicto. Todo ello para evitar un pensamiento único instalado en el mundo académico y que se manifiesta, según él, por una peligrosa «unanimidad» en cuanto a métodos, contenidos y discursos desarrollados tanto en la academia como en la sociedad que domina esos discursos. Frente a estos discursos dominantes, el autor prefiere hablar de afinidad. Entiende por ello: «En la práctica, la afinidad consiste en un grupo de personas que comparten una base común y que pueden proporcionar espacios de apoyo y de simpatía hacia sus miembros para articularse, escucharse unos a otros, y compartir preocupaciones, emociones o miedos. La política de la afinidad permite a las personas proporcionar apoyo y solidaridad unos a otros» (C, pp. 84-85). De este tipo de afinidad nacerá, también según el autor, la noción de consenso y de allí necesariamente la solidaridad mutua. Las emociones, «la vida interior de la política», vuelven a tener un protagonismo nunca imaginado, haciendo que el profesor (un agente pasivo según viejos modelos) se comprometa política y activamente con aquello que investiga, haciendo cosas con palabras: «Es nuestra capacidad para transformar nuestros sentimientos sobre el mundo en acciones lo que nos inspira a participar en la acción política» (C, p. 87). Las fronteras entre el académico y el activista se diluyen haciendo que la figura del experto también se borre por ser incompatible con la honestidad entre lo que se dice y lo que se hace.

En la misma línea, Luis A. Fernández defiende que siempre y cuando sea posible, el académico debería «estar allí» ejerciendo lo que él llama «observación participativa». Es importante estar allí donde hay problemas de interés para la academia porque uno puede entender de primera mano lo que ha estudiado y leído abstractamente durante años. Si se sigue este proceso se consigue, según Fernández, una estratégica reconciliación entre corazón y cerebro, sintetizándose en único órgano. De ese órgano hay que arrancar de cuajo el viejo mito de la objetividad para implantar en su lugar la compasión y la conectividad: «En lugar de desapego y objetividad deberíamos buscar, por el contrario, la conectividad y la compasión, valores que encajan bien tanto con la sensibilidad anarquista, como con la cooperación y la ayuda mutua» (C, p. 95). Este autor también apuesta por borrar las líneas entre participante, activista y escolar, defendiendo el uso del método inductivo: ir de lo particular a lo general, o: «En otras palabras, pasar 
de lo particular a lo general sin perder de vista lo que hace única a una circunstancia específica» (C, p. 97). Ahora cabe preguntarse: ¿Hay que renunciar con todo ello al rigor y cierto grado de profesionalidad en el mundo académico? La respuesta es negativa. Lo que hay que hacer es trabajar mediante una verdadera inmersión: «El objetivo era sumergirme a mí mismo en la protesta, convertirme en uno de los manifestantes, y desarrollar una comprensión teórica de la situación basada en esa inmersión. Si bien reconocía la imposibilidad de entrar en este campo como tabula rasa, yo intenté dejar de lado las ideas y las teorías académicas sobre el movimiento, esperando que ello produciría una experiencia profunda de la situación, dando como resultado una nueva valiosa información» (C, p. 98). El autor también propone introducir un término de Max Weber que incluye conexiones entre las intenciones, las pasiones y las vivencias de los objetos estudiados; ese término es el de Verstehen (C, p. 99). Con esa maniobra no se persigue vulgarizar las ciencias sociales sino hacerlas más cercanas y sentidas. Ello, por supuesto, exige una redefinición de lo que significa ser un intelectual anarquista.

Así, David Graeber advierte que quienes se autocalifican de anarquistas o de pensadores anarquistas están olvidando que pensamiento sin acción es algo socialmente irrelevante y, en consecuencia, una hipocresía. Su discurso dice así: si en la actualidad el anarquismo es aceptado como un movimiento que se mueve bajo los principios de un discurso ético sobre prácticas revolucionarias, entonces hay que actuar en coherencia con lo que se predica ( $C$, p. 106), cosa totalmente impensable en la universidad tradicional, empeñada, como decía Foucault, en la colonización de nuestras almas (C, p. 124).

Ante ese nuevo paradigma teórico y pedagógico siempre surgen reticencias $y$ ataques. Un ejemplo extremo lo encontramos en el ultraconservador Carl Schmitt. En uno de sus libros equiparaba al anarquista con la figura del partisano ${ }^{3}$. Éste aparece como un revolucionario profesional que no porta armas, ni uniforme, ni se ha instruido militarmente pero actúa ayudado por su grupo de gente, con extrema movilidad y con un compromiso individual intensísimo que le lleva a morir por sus ideales. Alguien podría objetar al respecto: ¿borrar las fronteras entre el mundo de la academia y el de la militancia anarquista no supone darle la razón a Schmitt convirtiendo al académico en algo parecido a un partisano en permanente estado de guerra? Para responder a semejante ataque podemos recurrir a las palabras de Norbert Elias quien afirmaba: «Únicamente los niños pequeños y, entre los adultos, tal vez los dementes, se comprometen absolutamente

3. Véase Schmitt, Carl, Teoría del partisano, Madrid, Centro de Estudios Políticos Constitucionales, 1966 
con su actitud y sus experiencias de modo que se abandonan sin condiciones a lo que sienten aquí y ahora; y también es únicamente entre los dementes donde podemos encontrar un distanciamiento absoluto; sólo ellos son capaces de mantener una total indiferencia hacia lo que sucede a su alrededor. Normalmente, el comportamiento de los adultos se encuentra dentro de una escala que oscila entre estos dos extremos» ${ }^{4}$. En consecuencia, debemos entender lo expuesto en Contemporary Anarchist Studies sólo como una serie de herramientas para luchar a través de la educación por un futuro igualitario, post-capitalista y post-estatal. Y, para ello, nada mejor que establecer el justo medio entre el distanciamiento y el compromiso: Compromiso por la paz, por la ecología, por la creación de formas de evitar la exclusión, la marginación y los abusos de poder, compromiso por la organización de la vida sin jerarquías y, en definitiva, compromiso por la construcción de un mundo mejor.

Finalmente, existe otra amenaza latente a la que ninguno de los autores ha perdido de vista: ¿No será este resurgir del anarquismo dentro de la academia un intento por parte del capitalismo por absorber, asimilar y, por tanto, neutralizar la presumible vitalidad e independencia de este movimiento? Contra ese presentimiento, seamos como el viejo Sócrates -parecen decir los colaboradores de este libro-, convirtámonos en activos tábanos que andan pinchando y avivando la conciencia revolucionaria adormecida de nuestros conciudadanos, de nuestros estudiantes y, sobre todo, de nosotros mismos. Y esto porque: «Incluso en el escenario más favorable, los anarquistas tendrán que responder a la reemergencia de patrones de dominación dentro de y/o entre comunidades incluso si éstos, en un determinado momento, han sido conscientemente superados. La vigilancia eterna seguirá siendo el precio de la libertad» (C, p. 257).

Pedro García Guirao

Instituto Cervantes de Praga

4. Elias, Norbert, Compromiso y distanciamiento. Ensayos de sociología del conocimiento, Barcelona, Ediciones Península, 2002, p. 20. 